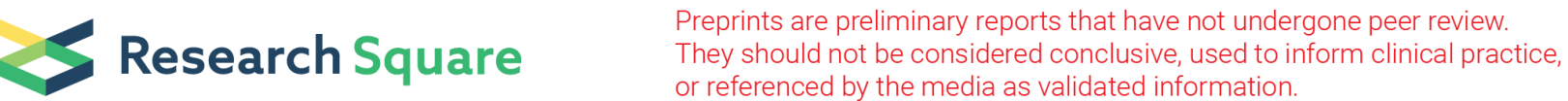 \\ Occupational inequalities in mortality in South Korea using nationally representative mortality follow-up data from the late 2000s and after
}

\section{Eunjeong Noh}

Seoul National University Institute of Health Policy and Management

\section{Young-Ho Khang ( $\square$ yhkhang@snu.ac.kr)}

Seoul National University College of Medicine https://orcid.org/0000-0002-9585-8266

\section{Short report}

Keywords: health inequalities, mortality, occupations, Republic of Korea, socioeconomic factors

Posted Date: August 19th, 2021

DOl: https://doi.org/10.21203/rs.3.rs-810209/v1

License: (c) (1) This work is licensed under a Creative Commons Attribution 4.0 International License.

Read Full License

Version of Record: A version of this preprint was published at Epidemiology and Health on April 6th, 2022. See the published version at https://doi.org/10.4178/epih.e2022038. 


\section{Abstract}

Many Korean and international studies have found higher mortality and poorer health conditions among manual workers than among non-manual workers. However, a recent study using unlinked data argued that since the economic crisis in Korea in the late 2000s, the mortality estimates of male Korean nonmanual workers have been higher than those of manual workers. Our work using individually linked data from the late 2000 s and after aimed to examine mortality inequality by occupational class.

We analyzed Korea National Health and Nutrition Examination Survey data that were individually linked to cause-of-death data. Cox regression analysis was used to identify the hazard ratios for mortality by occupational class.

Of 11,766 men aged between 35 and 64, 397 died between 2007 and 2018: 142 died from cancer, 68 from cardiovascular diseases, 88 from external causes, and 99 from other causes. After controlling for age, the mortality estimates for manual workers were 1.85 times higher than those for upper non-manual workers $(P<0.05)$.

We observed no evidence of reversed mortality inequality among occupational classes in Korea since the 2000s; this previously reported finding might have been due to numerator-denominator bias arising from the use of unlinked data.

\section{Introduction}

Non-manual workers are known to have better health and lower mortality rates than manual workers (17). However, a recent study using unlinked data reported that this general pattern appeared to be different in South Korea (hereafter, Korea) and Japan (8). That study claimed that Korean non-manual workers' mortality estimates have risen since the 2000s economic crisis, becoming higher than those of manual workers. This purported reversed occupational inequality in mortality could be attributed to a sharp increase in cancer- and suicide-related deaths among non-manual workers since the economic crisis (8). The authors of the study suggested that the national economic crisis in the late 2000s might have negatively influenced the health risk factors affecting non-manual workers' mortality. However, another recent study using data on men aged 35-64 in Korea from 2007 to 2009 found that socioeconomic indicators, such as education, income, parental education, and economic activity, as well as work environment indicators, were more favorable among non-manual workers than among manual workers, and the prevalence of unfavorable health-related behavioral indicators, such as smoking, high-risk alcohol consumption, depression, and suicidal ideation, was still higher among manual workers than among their counterparts (9). The previously reported finding of a reversed pattern of mortality inequality among occupational classes in Korea may have been caused by numerator-denominator bias since the study used population and death counts from different unlinked data sources (9-12). Although individually linked data from the late 1990s and early 2000s in Korea have provided evidence for occupational mortality inequalities favoring non-manual workers $(5,13,14)$, no research has been done 
using individually linked cohort data from the late 2000s. An analysis of linked cohort data from the late 2000 s to the late 2010 s could help determine whether there is in fact a reversed pattern of occupational inequality in mortality in Korea. This study aimed to determine mortality estimates by occupational class in Korea since the 2000s.

\section{Methods}

\section{Population and sample}

This study linked data from the 2007-2015 Korea National Health and Nutrition Examination Surveys (KNHANES) to the 2007-2018 cause-of-death data provided by the Korea Disease Control and Prevention Agency (KDCA). The KNHANES is an annual nationwide survey conducted to understand the health and nutritional status of Korean citizens based on Sect. 16 of the National Health Promotion Act (15). Of the 53,101 KNHANES respondents from 2007 to 2015, 51,603 (22,083 males, 29,520 females) consented to linkage with cause-of-death data and had valid unique personal identification numbers. Among them, 12,505 men aged 35-64 were eligible for the study purpose, as the prior study examined occupational mortality inequality among men aged 35-64 (8). With the exclusion of 739 individuals due to missing information on main indicators, the final sample included 11,766 individuals (15). Individual data linkage was performed internally at the KDCA, and data without any personal information were provided for our analysis.

\section{Variables}

The occupational information provided by the KNHANES from 2007 to 2015 was the independent variable. Four occupational groups were identified based on the same definition used by Tanaka et al. (8): the upper non-manual group included managers and professionals; the lower non-manual group included clerks and service and sales workers; the manual group included craft workers, plant and machine operators and assemblers, and elementary occupations; and the "others" group included workers in other jobs (e.g., agricultural, forestry and fishery workers and unemployed individuals). Data on all-cause and cause-specific deaths by occupation class between 2007 and 2018 were identified. Four major causes of death were considered, including cancer (ICD code: C00-D48), cardiovascular diseases (ICD code: I00-199), external causes (ICD-10 code: V01-Y89), and other causes.

\section{Analysis}

Using information on survival time and death status, Cox proportional hazards regression models were employed to analyze the hazard ratios of all-cause and cause-specific mortality among occupational classes, after adjusting for age.

\section{Results}

From 2007 to 2018,397 of the 11,766 individuals died (3.37\%): 142 (35.77\%) died from cancer (ICD codes: C00-D48), 68 (17.13\%) from cardiovascular diseases (100-199), 88 (22.17\%) from external causes 
(V01-Y89), and 99 (24.94\%) from other causes.

The all-cause mortality estimates of the manual workers after adjustment of age was 1.85 times higher than those of upper non-manual workers $(P<0.05)$. The hazard ratio of lower non-manual workers tended to be higher than that of upper non-manual workers (Table 1$)$.

Table 1

Hazard ratios (HRs, adjusted for age) and their 95\% confidence intervals (Cls) of all-cause mortality by occupational class in South Korean men aged 35 to $64(n=11,766)$ : mortality follow-up data from the 2007 and 2015 Korea National Health and Nutrition Examination Surveys

\begin{tabular}{|c|c|c|c|c|}
\hline & Number of subjects & Number of deaths & Hazard ratio $(95 \% \mathrm{Cl})$ & $P$ value \\
\hline Upper non-manual & 2276 & 35 & 1.00 & Reference \\
\hline \multirow[t]{2}{*}{ Lower non-manual } & 3069 & 52 & 1.31 & 0.28 \\
\hline & & & $(0.81-2.13)$ & \\
\hline \multirow[t]{2}{*}{ Manual } & 3931 & 121 & 1.85 & 0.01 \\
\hline & & & $(1.20-2.85)$ & \\
\hline \multirow[t]{2}{*}{ Others } & 2490 & 189 & 3.38 & $<.001$ \\
\hline & & & $(2.14-5.33)$ & \\
\hline
\end{tabular}

Cause-specific analysis results showed that, largely because of small numbers of cause-specific deaths, manual workers did not have statistically significantly higher cause-specific mortality estimates than upper non-manual workers. However, those in the "others" group, who were not classified as manual workers but were either agricultural, forestry, or fishery workers or were unemployed, had much higher mortality estimates (all statistically significant) than upper non-manual workers (Table 2). 
Table 2

Hazard ratios (HRs, adjusted for age) and their 95\% confidence intervals (Cls) of mortality from four broad causes by occupational class in South Korean men aged 35 to $64(n=11,766)$ : mortality follow-up data from the 2007 and 2015 Korea National Health and Nutrition Examination Surveys

\begin{tabular}{|c|c|c|c|c|}
\hline & $\begin{array}{l}\text { Upper non- } \\
\text { manual }\end{array}$ & $\begin{array}{l}\text { Lower non- } \\
\text { manual }\end{array}$ & Manual & Others \\
\hline No. of subjects & 2276 & 3069 & 3931 & 2490 \\
\hline No. of cancer deaths & 14 & 17 & 34 & 77 \\
\hline \multirow[t]{2}{*}{$\mathrm{HR}(95 \% \mathrm{Cl})$} & \multirow[t]{2}{*}{1.00} & 1.09 & 1.34 & 2.39 \\
\hline & & $(0.47-2.50)$ & $\begin{array}{l}(0.62- \\
2.90)\end{array}$ & $(1.19-4.79)$ \\
\hline P-value & Reference & 0.85 & 0.46 & 0.01 \\
\hline $\begin{array}{l}\text { No. of cardiovascular } \\
\text { deaths }\end{array}$ & 5 & 10 & 21 & 32 \\
\hline \multirow[t]{2}{*}{$\mathrm{HR}(95 \% \mathrm{Cl})$} & \multirow[t]{2}{*}{1.00} & 1.46 & 2.06 & 3.25 \\
\hline & & $(0.47-2.50)$ & $\begin{array}{l}(0.74- \\
2.90)\end{array}$ & $(1.10-4.79)$ \\
\hline P-value & Reference & 0.52 & 0.17 & 0.03 \\
\hline No. of external causes & 10 & 18 & 34 & 26 \\
\hline \multirow[t]{2}{*}{$\mathrm{HR}(95 \% \mathrm{Cl})$} & \multirow[t]{2}{*}{1.00} & 1.56 & 2.07 & 3.17 \\
\hline & & $(0.67-3.60)$ & $\begin{array}{l}(0.95- \\
4.51)\end{array}$ & $(1.25-8.06)$ \\
\hline P-value & Reference & 0.30 & 0.07 & 0.02 \\
\hline No. of other deaths & 6 & 7 & 32 & 54 \\
\hline \multirow[t]{2}{*}{$\mathrm{HR}(95 \% \mathrm{Cl})$} & \multirow[t]{2}{*}{1.00} & 1.11 & 2.53 & 5.79 \\
\hline & & $(0.30-4.16)$ & $\begin{array}{l}(0.80- \\
7.98)\end{array}$ & $\begin{array}{l}(1.80- \\
18.64)\end{array}$ \\
\hline P-value & Reference & 0.87 & 0.11 & $<0.001$ \\
\hline
\end{tabular}

\section{Discussion}

This study utilized cohort data that linked the 2007-2015 KNHANES data with 2007-2018 cause-ofdeath data. By tracking deaths and the causes of death in Korean men aged 35 to 64, all-cause mortality estimates according to occupational class and mortality estimates based on four causes of death were derived. Even after the economic crisis in the late 2000s, the mortality of male Korean manual workers aged 35 to 64 remained higher than that of non-manual workers. Therefore, there was no evidence to support the finding of reversed mortality inequality by occupational class reported by the previous study 
(8), which used unlinked census and death registry data. Our study is consistent with the universal conclusions of previous domestic and international studies using mortality follow-up data, which have shown that the mortality estimates of manual workers are higher than those of non-manual workers (17).

Additionally, the prior study proposed that the Korean economic crisis in the 2000s could have negatively affected non-manual workers' psychosocial health factors, such as stress and depression, which might have contributed to increased mortality due to suicide and cancer (8). However, although cause-specific mortality estimates were not statistically significantly higher in manual workers than in non-manual workers due to the small numbers of cause-specific deaths in the present study, the hazard ratios for cancer and external causes tended to be higher in manual workers than in non-manual workers (Table 2). The mortality estimates of the "others" group were exceptionally higher than those of non-manual workers, and this discrepancy was statistically significant. Moreover, our recent study using data from the late 2000s showed that psychosocial factors (e.g., depression, stress, suicidal ideation), work environment, and health behaviors related to cancer (e.g., smoking, high-risk alcohol consumption) were more favorable in non-manual workers than in manual workers (9).

In summary, like numerous previous studies on mortality and the prevalence of health risk factors by occupational class, this study found that in Korea, manual workers continued to have higher mortality rates than non-manual workers in the late 2000s and after. This result contradicts the prior claim of reversed mortality inequality by occupational class in Korea, which might be attributed to the denominator-numerator bias that has been commonly raised as a concern in health inequality research using unlinked data. If the census and death data by occupational class are not individually linked, as was the case in the study that proposed the inequality reversal, it is highly likely that the mortality estimates of non-manual workers will be overestimated and those of manual workers underestimated (912). Analyzing the linked data provided via the nationally representative KNHANES (2007-2015) and individual mortality data (2007-2018), this study confirmed that even after the economic crisis of the 2000s, patterns of mortality inequality in South Korea remain disadvantageous for those in lower occupational classes.

\section{Abbreviations}

\section{KNHANES}

Korea National Health and Nutrition Examination Surveys KDCA

Korea Disease Control and Prevention Agency

HRs

Hazard ratios

Cls

Confidence intervals 


\section{Declarations}

\section{Ethics approval and consent to participate}

Ethical approval for this study was received from the Seoul National University Hospital Institutional Review Board (IRB number: E-2006-058-1131).

\section{Consent for publication}

Not required.

\section{Availability of data and materials}

The data that support the findings of this study are available from Korea Disease Control and Prevention Agency but restrictions apply to the availability of these data, which were used under license for the current study, and so are not publicly available. Data are however available from the authors upon reasonable request and with permission of Korea Disease Control and Prevention Agency.

\section{Competing interests}

None declared.

\section{Funding}

This research was supported by a grant of the Korea Health Technology R\&D Project through the Korea Health Industry Development Institute (KHIDI), funded by the Ministry of Health \& Welfare, Republic of Korea (grant number: HI18C0446).

\section{Authors' contributions}

Conception: YHK. Study design: YHK, EN. Data analysis: EN. Supervision: YHK. Data interpretation: EN, YHK. Drafting manuscript: EN. Revising manuscript content: YHK, EN. Approval of the final version of the manuscript: YHK, EN.

\section{Acknowledgements}

We thank the Korea Disease Control and Prevention Agency for providing the linked data.

\section{References}

1. Mackenbach JP, Stirbu I, Roskam A-JRJR, Schaap MM, Menvielle G, Leinsalu M, et al. Socioeconomic inequalities in health in 22 European countries. N Engl J Med. 2008;358(23):2468-81.

2. Yeoman K, Sussell A, Retzer K, Poplin G. Health risk factors among miners, oil and gas extraction workers, other manual labor workers, and nonmanual labor workers, BRFSS 2013-2017, 32 States. 
Workplace Health Saf. 2020;68(8):391-401.

3. Toch-Marquardt M, Menvielle G, Eikemo TA, Kulhánová I, Kulik MC, Bopp M, et al. Occupational class inequalities in all-cause and cause-specific mortality among middle-aged men in 14 European populations during the early 2000s. PLoS One. 2014;9(9):e108072.

4. Stringhini S, Sabia S, Shipley M, Brunner E, Nabi H, Kivimaki M, et al. Association of socioeconomic position with health behaviors and mortality. J Am Med Assoc. 2010;303(12):1159-66.

5. Khang Y-H, Kim HR. Socioeconomic inequality in mortality using 12-year follow-up data from nationally representative surveys in South Korea. Int J Equity Health [Internet]. 2016;15(1):1-11. Available from: http://dx.doi.org/10.1186/s12939-016-0341-9

6. Khang YH, Kim HR. Relationship of education, occupation, and income with mortality in a representative longitudinal study of South Korea. Eur J Epidemiol. 2005;20(3):217-20.

7. Son M, Armstrong B, Choi JM, Yoon TY. Relation of occupational class and education with mortality in Korea. J Epidemiol Community Heal. 2002;56(10):798-9.

8. Tanaka H, Nusselder WJ, Bopp M, Brønnum-Hansen H, Kalediene R, Lee JS, et al. Mortality inequalities by occupational class among men in Japan, South Korea and eight European countries: A national register-based study, 1990-2015. J Epidemiol Community Health. 2019;73(8):750-8.

9. Noh E, Khang $\mathrm{Y}-\mathrm{H}$. Analysis of factors contributing to occupational health inequality in Korea: a cross-sectional study using nationally representative survey data. Arch Public Heal. 2021;79(1):1-8.

10. Khang $\mathrm{Y}-\mathrm{H}$. The surprising result of manual workers in Korea enjoying lower mortality than nonmanual workers is likely due to numerator-denominator bias [Internet]. J Epidemiol Community Health. 2019. Available from: https://jech.bmj.com/content/early/2019/06/07/jech-2018-211715.responses? versioned=true\#the-surprising-result-of-manual-workers-in-korea-enjoying-lower-mortality-than-nonmanual-workers-is-likely-due-to-numerator-denominator-bias

11. Kim H-R, Khang Y-H. Reliability of education and occupational class: A comparison of health survey and death certificate data. J Prev Med Public Heal. 2005;38(4):443-8.

12. Williams GM, Najman JM, Clavarino A. Correcting for numerator/denominator bias when assessing changing inequalities in occupational class mortality, Australia 1981-2002. Bull World Health Organ. 2006;84:198-203.

13. Khang Y-H, Lee S-I, Lee M-S, Jo M-W. Socioeconomic mortality inequalities in Korea labor \& income panel study. Korean J Heal Policy Adm. 2004;14(4):1-20.

14. Khang YH, Kim HR. Explaining socioeconomic inequality in mortality among South Koreans: An examination of multiple pathways in a nationally representative longitudinal study. Int J Epidemiol. 
2005;34(3):630-7.

15. Yun S, Oh K. Introduction to the Korea National Health and Nutrition Examination Survey (KNHANS) linked Cause of Death Data. Public Heal Wkly Rep. 2020;13(28):2071-80. 